\title{
Otimização de rotas utilizando o sistema de roteirização de código aberto XL Router
}

\author{
Route optimization using the open source routing system XL Router
}

\begin{abstract}
Resumo
Este artigo objetivou propor a utilização de um sistema de roteirização baseado no problema do caixeiro viajante de forma que fosse possível aplicalo de maneira prática a criação de uma nova proposta de rota a ser utilizada por uma empresa da área de distribuição e vendas de produtos gelados. Como procedimento metodológico foi utilizado uma pesquisa aplicada, telematizada e bibliográfica. Foi desenvolvido o sistema XL Router em VBA utilizando o suplemento OpenSolver para que a partir de um ponto de partida e uma série de pontos de parada fosse definida a menor rota possível, informando de maneira clara o tempo previsto para percorrer o percurso. O estudo concluiu que a utilização do sistema proposto alcançou o objetivo primordial de reduzir a quantidade de quilômetros percorridos e que de maneira eficiente gerou informações suficientes para auxiliar o processo de roteirização e que, pela redução do percurso, também permite a redução de custos associados ao processo de transporte e distribuição.
\end{abstract}

Palavras chave: Roteirizador. Excel. VBA. OpenSolver. Código Aberto.

\section{Abstract}

This article aims to propose the use of a routing system based on the problem of the traveling salesman so that it could applied in a practical way the creation of a new route proposal to use by a company in the area of distribution and sales of cold products. As methodological procedure, an applied, telematized and bibliographical research was used. The XL Router system developed in VBA with the OpenSolver supplement was used so that from a starting point and a series of stopping points the smallest possible route was defined, giving a clear indication of the expected time to travel the route. The study concluded that the use of the proposed system achieved the primary objective of reducing the number of kilometers traveled and that in an efficient way generated enough information to aid the routing process and that, by reducing the route, also allows the reduction of costs associated with process of transportation and distribution.

Keywords: Router. Excel. VBA. OpenSolver. Open Source. 


\section{Introdução}

Um dos maiores desafios que diariamente diversos operadores logísticos enfrentam é o de reduzir os custos de suas operações. Um dos processos que chama atenção justamente pelo seu custo elevado em face da quantidade de variáveis existentes é o de transporte. Entre custos fixos e variáveis é possível citar a manutenção dos veículos, combustível, frete entre outros.

Mesmo com a diversificação de sua matriz de transportes, o Brasil tem o transporte rodoviário como o modal mais utilizado, chegando a aproximadamente $2 / 3$ de utilização para o transporte de cargas. Apesar de muito utilizado, ainda sofre com os altos custos de operação. Lima (2014) lembra que os custos logísticos de transporte de 1.000 toneladas por quilometro útil deste modal giram em torno de US\$133,00.

Com a cotação atual (Abril/2017) do dólar próximo de $\mathrm{R} \$ 3,20$, temos que estes custos estariam chegando a $\mathrm{R} \$ 425,00$. Comparando estes valores com o modal aquaviário estes custos estariam na casa de $\mathrm{R} \$ 96,00$, com o modal dutoviário $\mathrm{R} \$ 80,00$ e com relação ao ferroviário o custo estaria próximo de $\mathrm{R} \$ 75,00$. O transporte rodoviário ficaria com valores inferiores apenas ao transporte aéreo em que seus custos logísticos atingem a casa de $\mathrm{R} \$ 3.392,00$.

Vale salientar que além do aspecto financeiro, há também os recursos humanos que ajudam a operacionalizar todo o processo logístico que nesse caso, compreende também os aspectos operacionais como a relação tempo de viagem e escala de trabalho, estresse, cansaço dentre outros.

Por se tratar do modal mais utilizado no território brasileiro e em termos relativos, também o mais custoso, é necessário que seja feito um planejamento minucioso de sua operação para que estes custos sejam reduzidos ao máximo. Uma das etapas do planejamento logístico do trans- porte rodoviário é a roteirização, que de maneira geral é definida como um problema de distribuição onde é proposto um ponto de partida (fornecedor), diversos pontos de parada (clientes) e o ponto de retorno, este último geralmente igual ao ponto de partida.

A roteirização é proposta como problema, pois há o desafio de se definir a menor rota possível de forma que atenda a todos os pontos de parada. Além disto, a medida que é inserido um ponto de parada em uma rota, as possibilidades de combinação para definir uma rota otimizada (menor distância) aumentam exponencialmente dependendo do número de conexões entre os pontos de parada, fazendo com que mesmo um computador com grande poder de processamento não consiga finalizar de maneira rápida os cálculos para informar a melhor rota.

Partindo desse problema, foi desenvolvido um sistema com código aberto em linguagem VBA associado ao suplemento utilizado para otimização linear, não linear e inteira OpenSolver que auxilia na resolução do problema da roteirização por meio da proposta existente no problema do caixeiro viajante (PCV). Utilizando a proposta do PCV, o sistema desenvolvido objetiva determinar a menor rota para visitar uma série de pontos de parada apenas uma vez em cada uma delas e após isso, retornar para o ponto de origem. Por se tratar de um problema operacional real, cotidiano e que afeta os custos empresariais, a realização deste artigo se justifica.

Esta pesquisa foi classificada de acordo com a proposta de Vergara (1998) que propõe os tipos de pesquisa quanto aos fins e quanto aos meios. Quanto aos fins trata-se de pesquisa aplicada já que é motivada pela necessidade de resolver problemas reais. Neste sentido, a pesquisa aplicada visa auxiliar a resolução de um problema de roteirização. Quanto aos meios trata-se de pesquisa telematizada por buscar informações em meios 
que utilizam sistemas como por exemplo, base de dados na internet. Assim, a pesquisa telematizada auxilia no processo de busca dos dados de distância entre a origem e os pontos de destino para que seja feita a roteirização. Trata-se também de pesquisa bibliográfica por ser desenvolvida com base em livros, revista cientificas e em material publicado de acesso ao público em geral.

\section{Roteirização de veículos}

Segundo Partyka e Hall (2000) "um problema real de roteirização é definido por decisões, objetivos e restrições”. De modo geral as decisões tem relação com a atribuição de um grupo de clientes que serão visitados pelos recursos (motoristas, caminhões, etc.) de maneira sequencial. Os objetivos buscam ofertar aos clientes um serviço de alto nível mantendo os custos mais baixos possíveis. No tocante as restrições, estas são para que as rotas sejam cumpridas com todos os recursos disponíveis respeitando os limites de tempo de jornada de trabalho, respeito às regras de trânsito, redução de distância percorrida, redução de tempo de viagem e que cada cliente seja visitado apenas uma vez

Dentre vários pontos, podem-se destacar os problemas que ocorrem ou que são gerados durante o processo de distribuição por canais diretos, indiretos ou reversos que expõe situações como atrasos nas entregas ou nas coletas, tamanho dos veículos incompatíveis com as vias públicas ou horários de carga e descarga influenciados pelos atrasos. Desta forma, a roteirização é parte fundamental no planejamento dos fluxos operacionais no momento da distribuição.

\subsection{Métodos para roteirização de veículos}

Para o gestor que deverá determinar qual a rota que deverá ser seguida, fazer esta pro- gramação torna-se cada vez mais complexo, já que à medida que são impostas novas restrições, o problema cresce em dificuldade. De maneira geral, há a questão primordial dos custos envolvidos nas operações de transporte que podem chegar a dois terços dos custos logísticos totais (Ballou, 2006).

Novaes (2007, p. 310) destaca o método de Varredura com um método "fácil de ser utilizado e de computação rápida”. Ballou (2006 p. 203) ratifica dizendo que "é simples ao ponto de prestarse a ser calculado a mão, mesmo ao tratar grandes problemas” e após os cálculos, representa um índice de erro máximo de $10 \%$. Tal erro pode ser aceitável dependendo do prazo que o responsável tem para desenvolver a rota de transporte.

É possível utilizar também o método ClarkeWright conhecido também como método das Economias. Assim como no método de varredura, Ballou (2006 p. 205) afirma que "o objetivo do método das economias é minimizar a distância total percorrida por todos os veículos e indiretamente minimizar o número de veículos necessários para servir a todas as paradas". Ballou (2006 p. 192) ainda informa que para resolução de problemas de roteirização, é possível utilizar o método do caminho mais curto que segundo o autor, esta "talvez seja a técnica mais simples e direta." Este método define o menor caminho entre os nós de origem e destino, sendo os nós os pontos de conexão entre as ligações. (Ballou, 2006).

Para a resolução do problema onde o ponto de origem é igual ao ponto de destino, de maneira que todos os clientes sejam atendidos tornando o percurso menor possível, há a possibilidade de utilizar a modelagem proposta no problema do caixeiro viajante (PCV). Este problema demonstra a situação de um caixeiro viajante que tem que visitar um determinado número de cidades localizadas numa região, devendo achar a sequência de pontos de parada de forma que ande o mínimo 
possível, passando apenas uma vez por cada cidade e retornando a cidade de origem ao final do percurso (Novaes, 2007). O PCV é um dos problemas de otimização combinatória mais estudados no mundo (Laporte, 1992, p. 231).

Apesar de sua declaração ser simples, sua resolução é complexa e se torna cada vez mais árdua a medida que são incluídos no roteiro novos pontos de parada (Novaes, 2007). Arenales, Armentano, Morabito e Yanasse (2015, p. 250) afirmam que o problema do caixeiro viajante "é um dos problemas combinatórios mais conhecidos e pesquisados devido à sua aplicação em diversas áreas, tais como manufatura de circuitos, programação da produção, telecomunicações e sequenciamento de DNA”.

Por ser um dos problemas mais conhecidos, é possível citar Taufer e Ferreira (2011) que apresentam uma forma de otimizar problemas de roteirização voltados à entrega de materiais para diversas localidades, baseado no problema do caixeiro viajante utilizando o Microsoft Excel / Solver como ferramenta de apoio. Também é possível mencionar Pereira, Duarte, Firmino, Irineu e Costa (2015), que por meio do software Logware, aplicaram a modelagem do problema do caixeiro viajante à distribuição de produtos de beleza de uma empresa do ramo de cosméticos.

O PCV é expresso por uma função objetivo que busca minimizar a distância total da rota. Alinhada a função objetivo, está a restrição que "impõe que cada cidade tenha somente uma cidade sucessora imediata e uma cidade predecessora imediata[...]" e também uma restrição “[...] que indica o tipo das variáveis". (Arenales, Armentano, Morabito \& Yanasse 2015, p. 250)

Belfiore e Fávaro (2012) propõe a seguinte modelagem para o problema do caixeiro viajante:

Variáveis de decisão:

$X i j=1$, se o caixeiro viajante vai diretamente $d a$ cidade $i$ para a cidade $j, i \neq j 0$, caso contrário
Função objetivo:

$$
\min \mathrm{z} i=1 n j=1 n C i j X i j
$$

Sujeito a:

$$
\begin{gathered}
i=1 n X i j=1 \quad \forall j \in N \\
j=1 n X i j=1 \quad \forall i \in N \\
i, j \in S n X i j \leq S-1 \quad \forall S \subset N \\
X i j \in 0,1\} \quad \forall i j \in N
\end{gathered}
$$

A função objetivo buscar minimizar o custo ou a distância a ser percorrida. As restrições 1 e 2 determinam que cada nó só poderá ser visitado uma vez. A restrição 3 impede que haja formação de sub-rotas. A restrição 4 determina que as variáveis de decisão sejam binárias (Belfiore, Fávaro, 2012).

Sendo $\mathrm{N}$ a quantidade de pontos de parada e substituindo este valor na fórmula $(N-1)$ ! é possível determinar a quantidade de rotas possíveis entre ponto de partida e pontos de parada. A Tabela 1 demonstra o crescimento exponencial do problema a medida que são incluídos novos pontos de parada sendo este crescimento exponencial um dos motivos para que o PCV seja considerado um tipo de "problema de otimização NP-Difícil” conforme demonstrado por Laporte (1992, p. 233). Levando em consideração a quantidade de conexões possíveis, nota-se que a resolução manual se torna inviável e que mesmo um computador que execute bilhões de cálculos por segundo demoraria muito tempo para terminar, já que a medida que se insere um ponto de parada a rota aumenta e o tempo de processamento é aumentado. 
Tabela 1: Crescimento da quantidade de rotas possíveis

\begin{tabular}{c|c}
\hline $\begin{array}{c}\text { Quantidade Pontos } \\
\text { de Parada }\end{array}$ & $\begin{array}{c}(\mathrm{N}-1) ! \\
\text { Quantidade de Rotas } \\
\text { Possíveis }\end{array}$ \\
\hline 5 & 24 \\
\hline 6 & 120 \\
\hline 7 & 720 \\
\hline 8 & 5.040 \\
\hline 9 & 40.320 \\
\hline 10 & 362.880 \\
\hline 20 & 121.645 .100 .408 .832 .000 \\
\hline 30 & 8.841 .761 .993 .739 .700 .000 .000$. \\
000.000 .000
\end{tabular}

Fonte: Autoria própria (2017)
O sistema XL Router ainda utiliza os dados cartográficos de distância e de tempo de viagem disponíveis no Google Maps. Para acesso a estes dados o Google disponibiliza as API's (Application Programming Interface ou Interface de Programação de Aplicativos). O sistema aproveita as API’s do Google Maps para traçar o mapa com a rota otimizada, proposta após a execução do problema. Além de gerar o mapa, também é possível imprimir a rota otimizada gerada após os cálculos. Na figura 1 é possível visualizar a tela inicial do sistema onde são lançados os parâmetros relativos ao itinerário.

\section{Sistema XL Router}

O sistema XL Router é um aplicativo baseado em linguagem VBA (Visual Basic For Applications). O VBA é um módulo de linguagem de programação para desenvolvedores que existe dentro dos softwares da suíte Microsoft Office (Dreux, Azevedo, 2009). Neste caso, o sistema foi desenvolvido dentro do módulo do Microsoft Excel. Buscando tornar sua utilização mais acessível ao grande público, o sistema foi implementado com uso de formulários (Windows Forms). O sistema manipula todos os dados utilizando as planilhas do Microsoft Excel.

Para determinar a melhor rota, o XL Router

Figural: Tela Inicial do XL Router

Fonte: Autoria própria (2017).

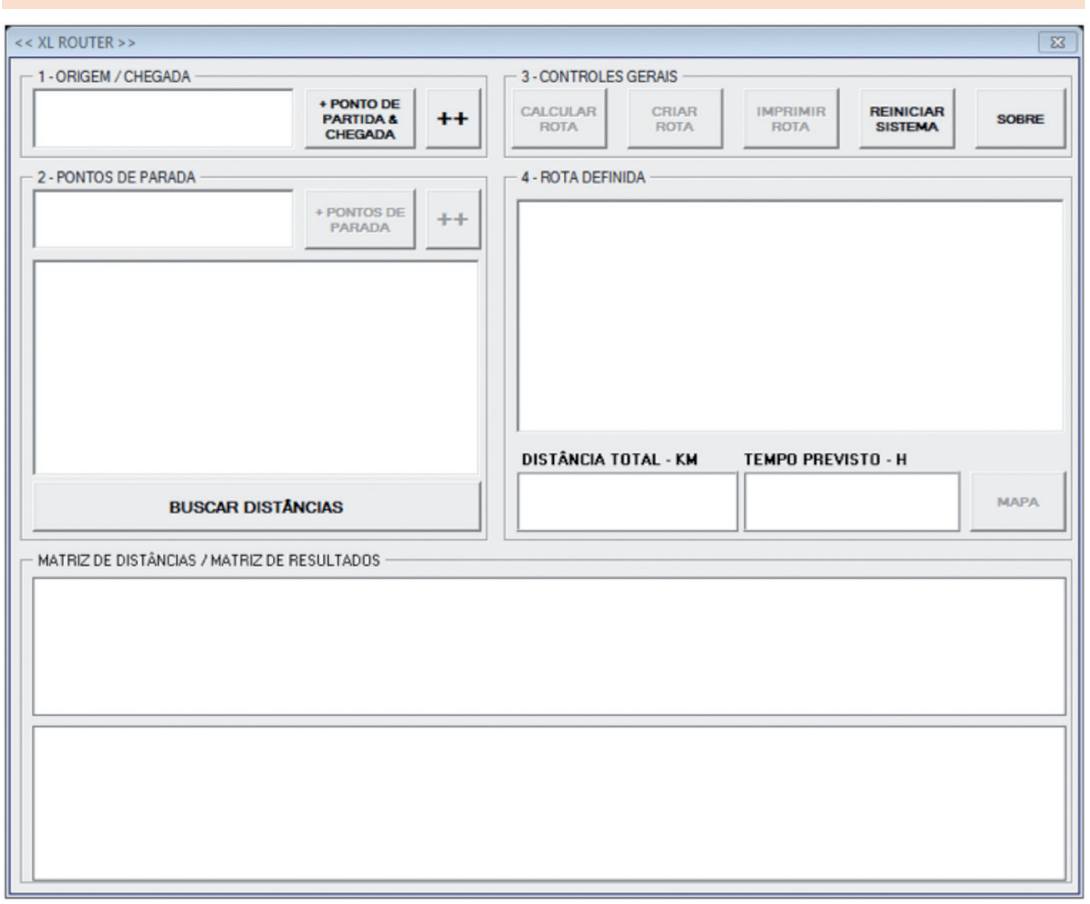
utiliza para auxiliar nos cálculos o suplemento do Microsoft Excel, OpenSolver. Similar ao suplemento nativo, Solver, o OpenSolver é uma solução gratuita sem limitações de uso. Funciona como um otimizador de código aberto para resolução de problemas de programação linear, inteira e não linear.
O funcionamento do sistema se dá por etapas:

a) Entrada dos dados de origem;

b) Entrada dos pontos de parada e busca das distâncias;

c) Cálculo e criação da rota otimizada;

d) Informações da rota, distância e tempo. 
Como foi dito anteriormente, o sistema busca as distâncias a partir das API's disponibilizadas pelo Google Maps para adquirir os dados necessários para o cálculo da rota, assim sendo, é indispensável uma conexão estável com a internet. Caso um ponto de parada não seja encontrado no servidor do Google Maps o próprio servidor retorna para o XL Router a distância igual a zero.

A partir do momento em que as distâncias entre os pontos de parada são encontradas, o sistema utiliza o OpenSolver para resolver o problema da roteirização de acordo com a modelagem do PCV. Concluindo os cálculos todas as informações relativas as distâncias e a rota já estarão disponíveis para visualização na matriz de distâncias em quilômetros e na matriz de resultados binários, todavia é possível visualizar os dados de maneira mais simplificada utilizando os dados interpretados nos relatórios e mapas que o sistema gera.

No caso do usuário utilizar constantemente o mesmo endereço, ou de desejar criar um cadastro com os possíveis pontos de partida ou parada o da área de distribuição de lácteos frescos (iogurte e requeijão) que iniciou suas atividades em 2004. Diariamente os vendedores partem de um ponto específico, e durante os dias da semana devem visitar uma série de clientes para confirmar os pedidos de compra dos supermercados.

As visitas acontecem durante os dias úteis da semana. Na simulação, foi utilizado o itinerário das visitas que acontecem às segundas feiras. De maneira empírica, o supervisor responsável define a rota levando em consideração apenas os horários de funcionamento ou atendimento caso haja algum tipo de restrição neste sentido, ou seja, basicamente não há um padrão a ser seguido pelo vendedor e, além disso, nenhum dado sobre quilometragem percorrida ou tempo para percorrer o percurso é avaliado.

Neste sentido, por haver um reembolso para o vendedor sobre os gastos de combustível, se faz necessário um controle maior sobre estas informações, principalmente no que tange a redução da quilometragem já que com essa redução, haveria um impacto sobre o valor pago ao vendedor. sistema conta com um registro de endereços mais utilizados. A figura 2 evidencia esta tela. Com um duplo clique no contato gravado o endereço completo é transferido para utilização na tela principal do sistema.

\section{Estudo de Caso}

Sabendo que a simulação é uma ferramenta essencial para aprimorar os processos logísticos (Bateman, Bowden, Gogg, Harrel, Mott \& Montevechi., 2013), foram utilizados dados reais fornecidos por uma empresa

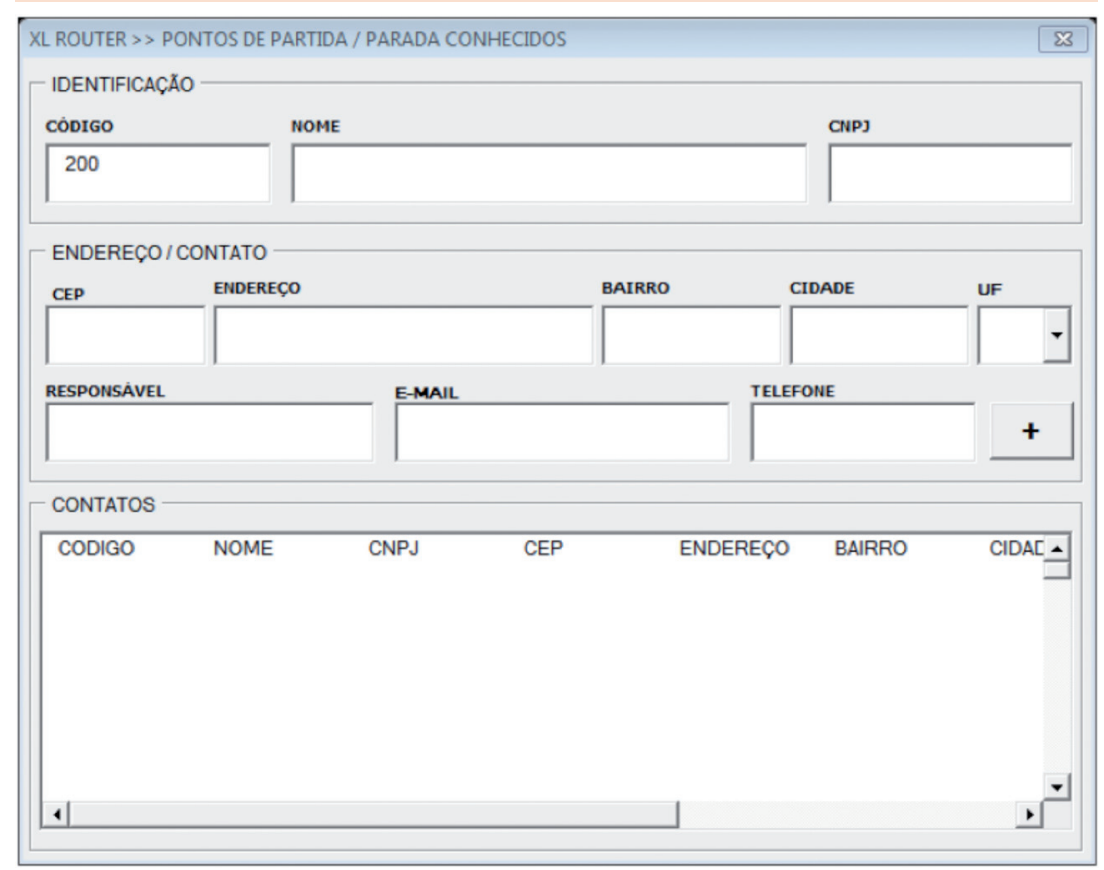

Figura 2: Registro para os pontos mais utilizados Fonte: Autoria própria (2017). 


\begin{tabular}{|c|c|c|}
\hline$\#$ & Cliente & Endereço \\
\hline 1 & Ponto de partida & $\begin{array}{c}\text { Av. Resplendor, Vila Velha } \\
\text { - ES }\end{array}$ \\
\hline 2 & Panificadora Pertim & $\begin{array}{c}\text { R. Antônio dos Santos Leão, } \\
168 \text { - Barra do Jucu, Vila } \\
\text { Velha - ES. }\end{array}$ \\
\hline 3 & $\begin{array}{l}\text { Remar Comércio } \\
\text { De Derivados Do } \\
\text { Trigo }\end{array}$ & $\begin{array}{l}\text { R. Vasco Coutinho, } 313 \text { - } \\
\text { Barra do Jucu, Vila Velha } \\
\text { - ES. }\end{array}$ \\
\hline 4 & $\begin{array}{l}\text { Mercearia E } \\
\text { Padaria Recanto } \\
\text { Da Sereia Lt }\end{array}$ & $\begin{array}{l}\text { Av. Central , } 191 \text { - Recanto } \\
\text { Da Sereia, Guarapari - ES. }\end{array}$ \\
\hline 5 & $\begin{array}{c}\text { R\&L Pereira Jercey } \\
\text { Minimercado E } \\
\text { Açougue }\end{array}$ & $\begin{array}{l}\text { R. Da Uva, } 17 \text { - Ponta Da } \\
\text { Fruta, Vila Velha - ES. }\end{array}$ \\
\hline 6 & Padaria Bom Gosto & $\begin{array}{l}\text { Avenida Anders, } 55 \text { - Nova } \\
\text { Itaparica, Vila Velha - ES. }\end{array}$ \\
\hline 7 & $\begin{array}{l}\text { Padaria e Auto } \\
\text { Serviço Nova } \\
\text { Itaparica }\end{array}$ & $\begin{array}{l}\text { R. Jardel Filho, } 35 \text { - Nova } \\
\text { Itaparica, Vila Velha - ES. }\end{array}$ \\
\hline 8 & B.M.Mercato Eireli & $\begin{array}{c}\text { Av. Santa Leopoldina, } \\
05 \text { - Praia de Itaparica, Vila } \\
\text { Velha-ES. }\end{array}$ \\
\hline 9 & $\begin{array}{c}\text { Padaria E } \\
\text { Confeitaria Wg }\end{array}$ & $\begin{array}{c}\text { Av. Saturnino Rangel Mauro, } \\
33 \text { - Praia Itaparica, Vila } \\
\text { Velha-ES. }\end{array}$ \\
\hline
\end{tabular}

Fonte: Autoria própria (2017).

De acordo com o Google Maps, o vendedor percorreria $65,8 \mathrm{~km}$ para visitar todos os clientes em um único dia e ao final voltar para o ponto de origem. Para fazer este roteiro, o vendedor gastaria aproximadamente 1h 49 minutos. Analisando a figura 3 é possível visualizar o percurso normal- ços é de suma importância, já que por um erro de digitação, as informações relativas às distâncias entre os pontos não serão encontrados na base de dados do Google Maps.

De maneira geral, recomenda-se que ao inserir os endereços, seja informado o logradouro (rua, avenida, alameda, etc.) junto do endereço original, o município e o estado. Assim sendo, com a inserção dos dados, o sistema busca as distâncias e efetua os cálculos necessários para que a rota otimizada seja gerada.

A figura 4 traz as informações consolidadas. $\mathrm{Na}$ tela do sistema (figura 4), no campo distância total, é especificada a quantidade de quilômetros que o vendedor percorreria e no campo adjacente o tempo previsto para percorrer a rota. Sendo $n=$ 9 é possível saber após aplicar este valor em [ $(\mathrm{N}-$ 1)!], que a quantidade de combinações possíveis poderia chegar a 40.320 dependendo das conexões entre estes pontos.

A tabela 3 traz informações da nova rota proposta pelo sistema além de informações com relação ao tempo e distância de percurso entre os pontos de parada. Debruçando sobre estes dados gerados pelo sistema, é possível notar na proposta de rota que há uma redução significativa no tempo de viagem bem como na quilometragem a ser rodada pelo vendedor caso opte por seguir esta roteirização. mente percorrido pelo vendedor as segundas-feiras.

\subsection{Proposta de otimização da rota e resultados obtidos}

Para otimização da rota, foi utilizado o sistema XL Router, utilizando as restrições na proposta no PCV aplicando as mesmas configurações de pontos de partida e pontos de parada. O momento de inserção dos endere-

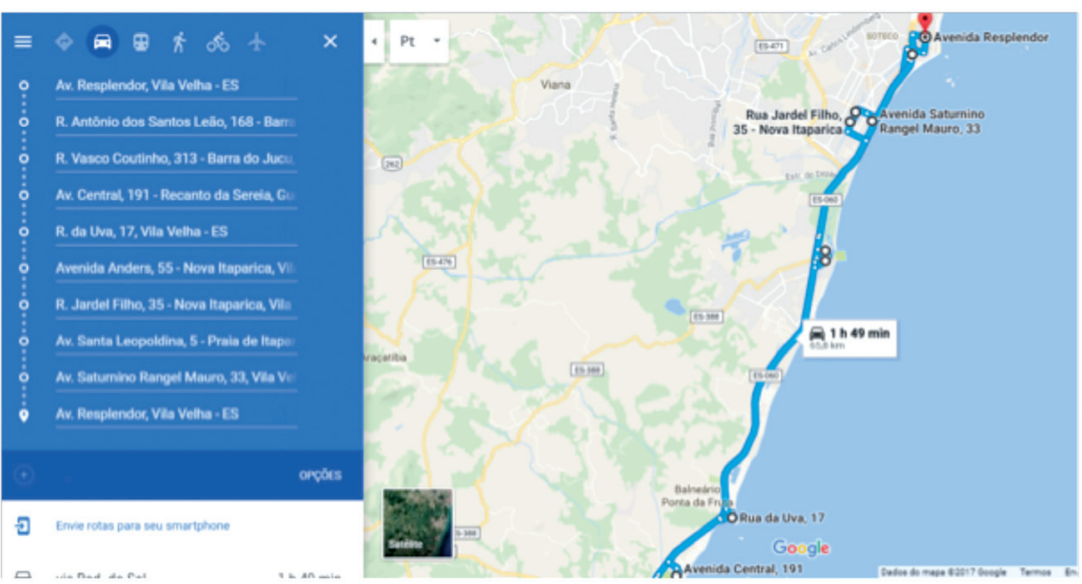

Figura 3: Distância percorrida Fonte: Google Maps. 


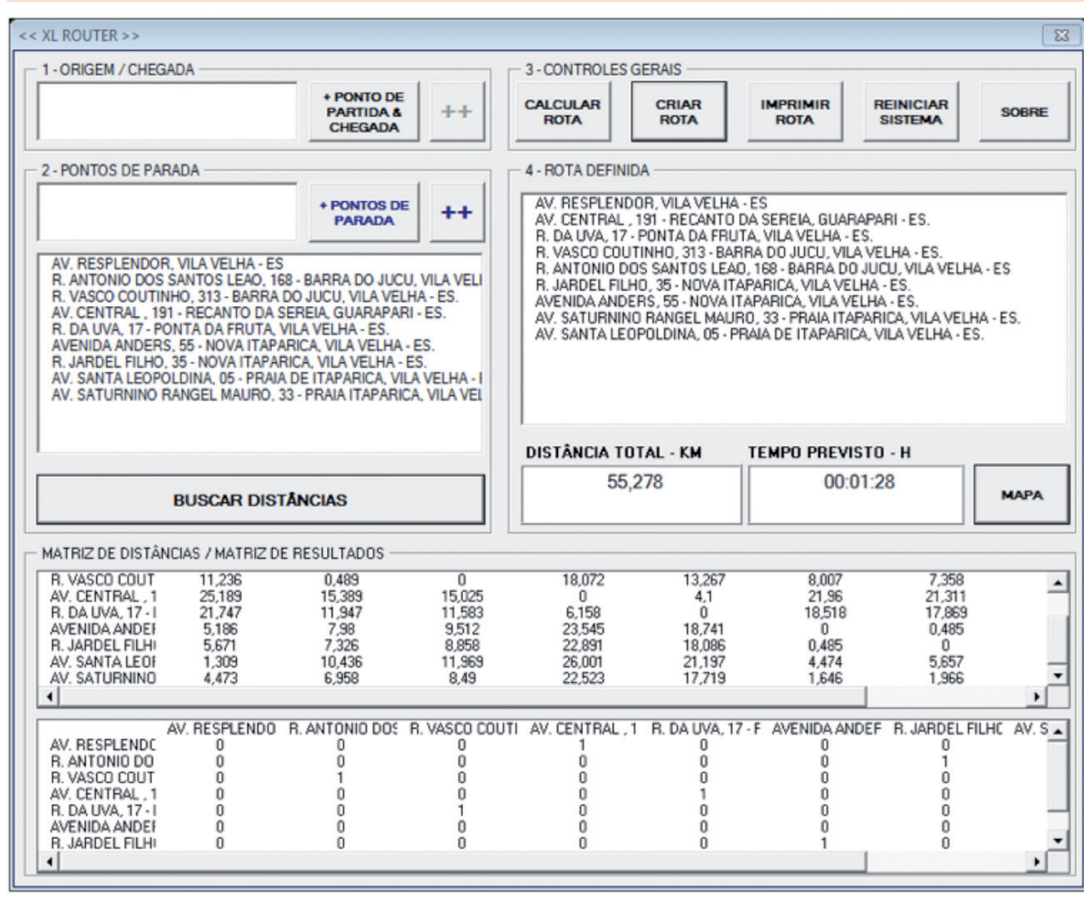

Figura 4: Informaçōes geradas pelo XL Router

Fonte: Autoria própria (2017).

Tabela 3: Proposta de nova ordem de atendimento dos clientes de segunda-feira

\begin{tabular}{|c|c|c|c|c|}
\hline$\#$ & Cliente & Endereço & Tempo & Distância \\
\hline 1 & Ponto de partida & $\begin{array}{l}\text { Av. Resplendor, } \\
\text { Vila Velha - ES }\end{array}$ & 0 & 0 \\
\hline 2 & $\begin{array}{c}\text { Mercearia E } \\
\text { Padaria Recanto } \\
\text { Da Sereia Lt }\end{array}$ & $\begin{array}{l}\text { Av. Central, } 191 \text { - Recanto } \\
\text { Da Sereia, Guarapari - ES. }\end{array}$ & 34 & 26,8 \\
\hline 3 & $\begin{array}{c}\text { R\&L Pereira Jercey } \\
\text { Minimercado E } \\
\text { Açougue }\end{array}$ & $\begin{array}{l}\text { R. Da Uva, } 17 \text { - Ponta Da } \\
\text { Fruta, Vila Velha - ES. }\end{array}$ & 8 & 4,1 \\
\hline 4 & $\begin{array}{c}\text { Remar Comércio } \\
\text { De Derivados } \\
\text { Do Trigo }\end{array}$ & $\begin{array}{l}\text { R. Vasco Coutinho, } \\
313 \text { - Barra do Jucu, Vila } \\
\text { Velha - ES. }\end{array}$ & 12 & 11,6 \\
\hline 5 & $\begin{array}{l}\text { Panificadora } \\
\text { Pertim }\end{array}$ & $\begin{array}{c}\text { R. Antônio dos Santos } \\
\text { Leão, } 168 \text { - Barra do Jucu, } \\
\text { Vila Velha - ES. }\end{array}$ & 6 & 0,5 \\
\hline 6 & $\begin{array}{l}\text { Padaria e Auto } \\
\text { Serviço Nova } \\
\text { Itaparica }\end{array}$ & $\begin{array}{l}\text { R. Jardel Filho, } 35 \text { - Nova } \\
\text { Itaparica, Vila Velha - ES. }\end{array}$ & 11 & 6,3 \\
\hline 7 & $\begin{array}{l}\text { Padaria Bom } \\
\text { Gosto }\end{array}$ & $\begin{array}{l}\text { Avenida Anders, } 55 \text { - Nova } \\
\text { Itaparica, Vila Velha - ES. }\end{array}$ & 2 & 0,5 \\
\hline 8 & $\begin{array}{c}\text { Padaria E } \\
\text { Confeitaria Wg }\end{array}$ & $\begin{array}{c}\text { Av. Saturnino Rangel } \\
\text { Mauro, } 33 \text { - Praia } \\
\text { Itaparica, Vila Velha - ES. }\end{array}$ & 4 & 1 \\
\hline 9 & $\begin{array}{l}\text { B.M.Mercato } \\
\text { Eireli }\end{array}$ & $\begin{array}{c}\text { Av. Santa Leopoldina, } \\
05 \text { - Praia de Itaparica, Vila } \\
\text { Velha - ES. }\end{array}$ & 7 & 3,3 \\
\hline 10 & $\begin{array}{l}\text { Ponto de } \\
\text { chegada }\end{array}$ & $\begin{array}{l}\text { Av. Resplendor, } \\
\text { Vila Velha-ES }\end{array}$ & 5 & 1,2 \\
\hline \multicolumn{3}{|c|}{ TOTAL } & $01 \mathrm{~h} 28 \mathrm{~min}$ & 55,27 \\
\hline
\end{tabular}

Fonte: Autoria própria (2017).
A redução no tempo de viagem é de extrema importância, já que a partir dela há a possibilidade do vendedor se dedicar a outras atividades de maneira que produza algo benéfico para a empresa para a qual trabalha e não perca seu tempo no trânsito dirigindo. Além disto, fatores emocionais também podem ser relacionados, pois há questões como o estresse no trânsito originando-se de riscos como acidentes ou assaltos que devem ser levados em consideração.

A tabela 4 compara as duas situações e informa a variação existente entre a rota original e a rota proposta. O campo tempo original expõe o tempo de viagem gasto em minutos a partir da roteirização feita pelo supervisor responsável, já o campo tempo proposta informa o tempo de viagem a partir da roteirização feita pelo sistema. Caso opte por seguir a rota proposta, o vendedor reduziria seu tempo de viagem em 21 minutos. Essa redução se aproxima da casa dos $20 \%$ comparando com a proposta original.

Vale salientar que a redução do tempo se dá pela redução direta na quantidade de quilômetros a serem viajados e não pelo aumento da velocidade do motorista que estiver dirigindo o veículo.

Ao que tudo indica, esta redução significativa se estende também a quantidade de quilômetros rodados. A redução da 
Tabela 4: Comparativo entre o tempo de percurso original e da proposta

\begin{tabular}{c|c|c|c}
\hline Ponto & $\begin{array}{c}\text { Tempo } \\
\text { Original }\end{array}$ & $\begin{array}{c}\text { Tempo } \\
\text { Proposta }\end{array}$ & Variação \\
\hline 1 |---- 2 & 23 & 34 & 11 \\
\hline 2 |---- 3 & 2 & 8 & 6 \\
\hline 3 |---- 4 & 21 & 12 & -9 \\
\hline 4 |---- 5 & 8 & 6 & -2 \\
\hline 5 |----- 6 & 22 & 11 & -11 \\
\hline 6 |---- 7 & 2 & 2 & 0 \\
\hline 7 |---- 8 & 11 & 4 & -7 \\
\hline 8 |---- 9 & 9 & 7 & -2 \\
\hline 9 |---- 1 & 11 & 5 & -6 \\
\hline TOTAL & $01 \mathrm{~h} 49 \mathrm{~min}$ & $01 \mathrm{~h} 28 \mathrm{~min}$ & $00 \mathrm{~h} 21 \mathrm{~min}$ \\
\hline
\end{tabular}

Fonte: Autoria própria (2017).

quilometragem a ser rodada, assim com a do tempo de viagem é de extrema importância tanto para a empresa quanto para o empregado. Com esta diminuição os custos associados ao transporte são diretamente reduzidos. Custos como, consumo de combustível, tempo de viagem e manutenção dos veículos são absolutamente afetados quando há um acréscimo ou decréscimo na distância a ser percorrida.

A tabela 5 descreve o comparativo entre as propostas, a original e a nova. O campo distância original expõe a distância em quilômetros a partir da roteirização feita pelo supervisor responsável, já o campo distância proposta informa a distância a partir da roteirização feita pelo sistema. Seguindo a proposta da nova rota, haveria uma redução de $10,6 \mathrm{~km}$ na quantidade de quilômetros rodados. Isso geraria uma redução de $16 \%$ com relação à proposta original.

É necessário enfatizar que esta redução se dá obedecendo à necessidade de visitar todos os clientes no máximo uma vez, percorrendo a me- nor quantidade de quilômetros e voltando ao ponto de origem ao final do trajeto. A figura 5 exibe o mapa com a nova rota plotada bem como os dados de distância e de tempo de viagem.

\begin{tabular}{|c|c|c|c|}
\hline Ponto & $\begin{array}{c}\text { Distância } \\
\text { Original }\end{array}$ & $\begin{array}{l}\text { Distância } \\
\text { Proposta }\end{array}$ & Variação \\
\hline $1 \mid----2$ & 11,3 & 26,8 & 15,5 \\
\hline $2 \mid----3$ & 0,5 & 4,1 & 3,6 \\
\hline $3 \mid----4$ & 18,1 & 11,6 & $-6,5$ \\
\hline 4 |----- 5 & 4,1 & 0,5 & $-3,6$ \\
\hline $5 \mid----6$ & 18,5 & 6,3 & $-12,2$ \\
\hline $6 \mid-----7$ & 0,5 & 0,5 & 0 \\
\hline $7 \mid-----8$ & 4,5 & 1 & $-3,5$ \\
\hline $8 \mid-----9$ & 3,9 & 3,3 & $-0,6$ \\
\hline 9 |----- 10 & 4,5 & 1,2 & $-3,3$ \\
\hline TOTAL & 65,9 & $55,27 \mathrm{Km}$ & $-10,6 \mathrm{Km}$ \\
\hline
\end{tabular}

Fonte: Autoria própria (2017).

\section{Figura 5: Mapa elaborado com a nova rota} Fonte: Google Maps.

\section{Considerações finais}

O planejamento das atividades logísticas deve ser item primordial na agenda de gestores que desejam reduzir seus custos operacionais. Como foi dito, os custos logísticos relacionados ao transporte chegam a atingir $2 / 3$ do total dos custos totais de uma operação de distribuição. 
No presente estudo foi utilizado o sistema XL Router para demonstrar a resolução de um problema de roteirização com base nas restrições do problema do caixeiro viajante. Após a inserção dos dados e cálculos do sistema, foi gerada uma nova rota, que, ao ser comparada com a rota executada normalmente pela empresa foco do estudo de caso, reduziu a quantidade de tempo de viagem em aproximadamente $20 \%$ e com relação a distância a redução chegou a $16 \%$. Assim sendo, é possível comparar os resultados de distância obtidos com a abordagem de Taufer e Ferreira (2011) que alcançaram a redução de 33,41\%. Pereira, Duarte, Firmino, Irineu e Costa (2015) também otimizaram o itinerário, reduzindo a distância percorrida em $30,56 \%$.

Se adotada como nova rota, e analisada em uma escala que envolva outros vendedores em outras rotas, estas reduções de tempo e quilometragem podem ser convertidas em uma economia considerável de custos relacionados a combustível e manutenção dos veículos. No que tange a questões sociais e ambientais, é possível citar a possibilidade da redução de emissão de gases poluentes provenientes dos veículos bem como a redução dos níveis de estresse dos empregados, por possivelmente passar menos tempo no trânsito.

Assim sendo, a utilização do sistema XL Router para roteirização se mostrou eficiente para gerar rotas otimizadas e úteis para o processo de planejamento do processo de distribuição. Logo, é possível concluir que sua utilização é válida, pois traz informações fidedignas para o processo de planejamento e que se acatadas, podem resultar em reduções de custos reais à realidade da empresa que o utilizar.

\section{Referências}

Arenales, Marcos; ARMENTANO, Vinícius; Morabito, e Reinaldo, Yanasse, Horacio. (2015). Pesquisa

operacional para os cursos de engenharia ( 2 a ed.). Rio de Janeiro: Elsevier.

Ballou, Ronald H. (2006). Gerenciamento da sadeia de suprimentos (5a ed.) Porto Alegre: Bookman.

Bateman, Robert E., Bowden, Royce O., Gogg, Thomas J., Harrel, Charles R., Mott, Jack R. A., Montevechi, José A. B. (2013). Simulação de sistemas: aprimorando processos de logística, serviços e manufatura. Rio de Janeiro: Elsevier.

Belfiore, Patricia; \& Fávero, Luiz Paulo. (2012). Pesquisa operacional para cursos de administração, contabilidade e economia. Rio de Janeiro: Elsevier.

Dreux, Marcelo \& Azevedo, Fernando Uilherme Barbosa de. (2009). Macros para Excel na prática. Rio de Janeiro: Elsevier.

Laporte, G. (1992). The traveling salesman problem: an overview of exact and approximate algorithms. European Journal Of Operational Research, 59, p. 231-247.

LIMA, Maurício. (2014). Custos logísticos no Brasil. Recuperado em 28 de abril, 2017, de http://www.ilos. com.br/web/custos-logisticos-no-brasil/.

Novaes, Antônio Galvão. (2007). Logística e gerenciamento da cadeia de distribuição. Rio de Janeiro: Elsevier.

Partyka, J. G., \& Hall, R. W. (2000). On the Road to service. OR/MS Today, 4, 26-30.

PEREIRA, Liviam Silva Soares; Duarte, Rafael Bezerra Duarte; Firmino, Cedma Ranielly Santos; Irineu, Anna Beatriz Maia, e Costa, João Rafael Agripino. (2015). Otimização de rota na distribuição de produtos em uma empresa de produtos de beleza. Recuperado em 06 de março de 2018, de http://www.abepro.org.br/biblioteca/ TN_STP_206_222_28184.pdf

Taufer, Fernando Soares Gomes, e Pereira, Elaine Correa. (2011). Aplicação do problema do caixeiro viajante na otimização de roteiros. Recuperado em 06 de março, 2018, de http://www.abepro.org.br/biblioteca/ enegep2011_TN_STO_140_885_18795.pdf

Vergara, Sylvia Constant. (1998). Projetos e relatórios de pesquisa em administração (2a ed.). São Paulo: Atlas.

XL ROUTER. (2017). Sistema de roteirização Open Source baseado em VBA. Recuperado em 06 de maio, 2017, de https://xlrouter.wordpress.com/.

Recebido em 7 dez. 2017 / aprovado em 13 mar. 2018

Para referenciar este texto

Martins, F. S. Otimização de rotas utilizando o sistema de roteirização de código aberto XL Router. Exacta, São Paulo, v. 16, n. 4, p. 115-124. out./dez. 2018. Disponível em: <https://doi.org/10.5585/ExactaEP. v16n4.8141> 